Elsworth, J. D., Dewar, D. Glover, V., Goodwin, B. L. Clow, A. \& SANDLER, M. (1986) Purification and characterisation of tribulin, an endogenous inhibitor of monoamine oxidase and of benzodiazepine receptor binding. Journal of Neural Transmission, 67, 45-56.

Petursson, H., Bhattacharya, S. K., Glover, V., Sandler, M and LADER, M. H. (1982) Urinary monoamine oxidase inhibitor and benzodiazepine withdrawal. British Journal of Psychiatry. 140, 7-10.

SANDLER, M. (1982) The emergence of tribulin. Trends in Pharmacological Sciences, 3, 471-472.

\section{HLA-DR2 and Sleep Onset REM Periods in} Endogenous Depression

SIR: With rare exceptions (Zietz et al, 1986), almost all patients with narcolepsy are HLA-DR2 positive (Billiard \& Seignalet, 1985), while the normal population frequency is about $20-35 \%$. To date, this association constitutes the strongest relationship between a given disease and the HLA-system.

Besides clinically relevant symptoms such as cataplexy, excessive daytime somnolence, hypnagogic hallucinations, and sleep paralysis, one main feature of narcolepsy is the occurrence of sleep onset REM periods (SOREMPs) (REM latency $\leq 25 \mathrm{~min}$ ) during daytime and night-time sleep. Recently, a correlation between length of REM latency and possession of HLA-DR2 was reported (Schulz et al, 1986). Healthy subjects who were HLA-DR2 positive exhibited significantly shorter REM latencies than those who were not positive. However, this result could not be replicated (Schulz et al, 1987).

The fact that narcoleptic patients and patients with endogenous depression share one common feature in their sleep pattern, i.e. the occurence of sleep onset REM periods, stimulated us to investigate HLA-DR2 in patients with endogenous depression, to clarify if there is a common genetic basis for this deviant sleep pattern.

We have investigated 11 patients with a major depressive disorder of the endogenous subtype according to Research Diagnostic Criteria (Spitzer et al, 1977). Seven of them were female, four were male. Mean age ( \pm s.d.) was $49.6 \pm 8.4$ years. Two of the patients were bipolar II, one patient was bipolar I. Blood samples for HLA-DR2 typing were drawn during a hospital stay and analysed using the microlymphocytotoxicity test according to the method of Terasaki.

All of the patients took part in ongoing sleep studies in our sleep laboratory, and had between two and five nights of baseline sleep recordings. The patients were free of any kind of psychoactive medication prior to sleep recording for at least seven days.

Seven of the patients had at least one sleep onset REM period. Four of them were HLA-DR2 positive, three were negative. Of the four patients showing no sleep onset REM periods, three were HLA-DR2 positive. Calculating a Fisher exact test for the occurrence of SOREMPs (yes/no) and HLA-DR2 positive/ negative, a $P$ value of 0.42 was attained. This result clearly contradicts the asumption that there is a close relationship between HLA-DR2 positive and sleep onset REM periods in endogenous depression.

Strikingly, however, the HLA-DR2 positive rate of $64 \%$ in our sample ( 7 of 11 patients were positive) of depressed patients by far exceeded the normal population rate of $20-35 \%$. Before definite conclusions can be drawn from this result, larger samples of depressed patients and patients with other psychiatric disorders must be investigated, to clarify whether this result is due to chance or sample selection.

Dieter RIEMANN MATHIAS BERGER

Psychiatric Clinic

Central Institute of Mental Health

Mannheim

West Germany

2nd Medical Clinic

Mannheim

University of Heidelberg

\section{References}

Billiard, M. \& Seignalet, J. (1985) Extraordinary association between HLA-DR2 and narcolepsy. The Lancet, i, 226-227.

Schulz, H., Geisler, P., Pollmaecher, T., Zietz, A., Keller, E., SCHOLZ, S. \& ALBERT, E. (1986) HLA-DR2 correlates with rapid eye movement sleep latency in normal human subjects. The Lancet, ii, 803.

- - (1987) HLA-DR2 and rapid eye movement sleep latency: failure to replicate. The Lancet, ii, 627.

Spitzer, R. L., Endicotr, J. E. \& Robins, E. (1977) Research Diagnostic Criteria for a Selected Group of Functional Disorders (3rd edn). New York: National Psychiatric Institute, Biometric Research Department.

Zietz, A., Keller, E., Scholz, S., Albert, E., Roth, B., Nevimalowa, S., Sonka, K., Docekal, P., Ivaskova, E., SCHULz, H. \& GeISLER, P. (1986) DR2-negative narcolepsy. The Lancet, ii, 684-685.

\section{Mystical-Ecstatic and Trance States}

SIR: Mystical-ecstatic and trance states fall within the general category of depersonalisation symptom and dissociative states. Usually they are pleasant, relaxing, short-lived, and do not have psychopathological consequences (Benson, 1984).

Case report: $\mathrm{Mr}$ A, a 26-year-old right-handed man, had a life-long interest in mystical and religious philosophy, 